\title{
Surgery for hypertrophic cardiomyopathy
}

\author{
James J. Wu • Michael Seco • Caroline Medi • Chris Semsarian • \\ David R. Richmond • Joseph A. Dearani • Hartzell V. Schaff • \\ Michael J. Byrom • Paul G. Bannon
}

Received: 22 October 2014 / Accepted: 25 November 2014 /Published online: 10 January 2015

(C) International Union for Pure and Applied Biophysics (IUPAB) and Springer-Verlag Berlin Heidelberg 2015

\begin{abstract}
Hypertrophic cardiomyopathy (HCM) is a genetically determined cardiac disease characterised by otherwise unexplained myocardial hypertrophy of the left ventricle, and may result in left ventricular outflow tract obstruction. It is the most common cause of sudden cardiac death in young adults due to arrhythmias. Septal myectomy is a surgical treatment for HCM with moderate to severe outflow tract obstruction, and is indicated for patients with severe symptoms refractory to medical therapy. The surgical approach involves obtaining access to the interventricular septum via transaortic, transapical or transmitral approaches, and excising a portion of the hypertrophied myocardium to relieve the outflow tract obstruction. Large, contemporary series from centres experienced in septal myectomy patients have demonstrated a low early mortality of $<2 \%$, excellent long-term survival that
\end{abstract}

\section{J. J. Wu $\cdot$ M. Seco $\cdot$ C. Semsarian • P. G. Bannon}

Sydney Medical School, The University of Sydney, Sydney,

Australia

J. J. Wu • M. Seco • M. J. Byrom • P. G. Bannon $(\varangle)$

The Baird Institute of Applied Heart \& Lung Surgical Research,

Sydney, Australia

e-mail:pgbannon@gmail.com

J. J. Wu $\cdot$ M. Seco $・$ M. J. Byrom • P. G. Bannon

Cardiothoracic Surgery Unit, Royal Prince Alfred Hospital, Sydney,

Australia

\section{Medi $\cdot$ C. Semsarian}

Molecular Cardiology Group, Centenary Institute, Sydney, NSW, Australia

C. Medi • C. Semsarian • D. R. Richmond

Department of Cardiology, Royal Prince Alfred Hospital, Sydney, NSW, Australia

J. A. Dearani $\cdot$ H. V. Schaff

Cardiac Surgery Unit, Mayo Clinic, Rochester, MN, USA matches the general population, and durable relief of symptoms.

Keywords Hypertrophic cardiomyopathy · Septal myectomy $\cdot$ Alcohol septal ablation $\cdot$ Left ventricular outflow tract obstruction

\section{Introduction}

Hypertrophic cardiomyopathy (HCM) is a disease of the myocardium characterised by hypertrophy of the left ventricle that is greater than or equal to $15 \mathrm{~mm}$ in diameter (greater than or equal to $13 \mathrm{~mm}$ in patients with a known family history). The disease occurs in 1 in 500 of the general population (Maron et al. 1995), and is the result of a mutation in 1 or more of the 11 identified genes that encode components the cardiac sarcomere complex (Maron et al. 2012). It is associated with a heterogeneous clinical presentation that varies from an absence of symptoms to severely disabling symptoms of fatigue, dyspnoea, chest pain, syncope and sudden cardiac death (SCD). The overall mortality rate of patients with HCM is less than $1 \%$ per year, most commonly the result of SCD due to ventricular arrhythmias (Nishimura and Holmes 2004). It is the most common cause of SCD in young athletes (Maron and Maron 2013). Patients with HCM can be divided into those with and without left ventricular outflow tract obstruction (LVOTO). In this review, we will be directing our discussion to the group with LVOTO. For these patients, pharmacotherapy is the first-line treatment (Spoladore et al. 2012). Septal reduction therapy is indicated for patients who have significant LVOTO with refractory symptoms on medical therapy, and can be achieved through surgical myectomy or percutaneous alcohol septal ablation (ASA). 


\section{Anatomical classification}

Since the early 1970s, echocardiography has provided a noninvasive diagnostic tool to identify patients with HCM, leading to a comprehensive understanding of the diverse nature of the disease (Wigle et al. 1995). HCM patients are classified as having obstruction based on (1) the measurement of peak systolic velocity in the left ventricular outflow tract (LVOT) at rest and in some cases after provocation, (2) systolic anterior motion (SAM) of the anterior leaflet of the mitral valve resulting in a posteriorly directed jet of regurgitation, and (3) mid-systolic closure of the aortic valve (Klues et al. 1995). From a surgical perspective, classical HCM patients can be further sub-classified on the basis of the site of maximum septal hypertrophy, although other wall segments are usually also hypertrophied:

- Subaortic HCM-hypertrophy of the basal interventricular septum that creates a relatively elliptical left ventricular (LV) cavity with a marked nodule. This results in LVOTO caused by SAM.

- Midventricular HCM - midseptal hypertrophy that forms a crescent-shaped LV cavity and may be also associated with SAM and LVOTO

- Apical HCM - a predominantly apical distribution of hypertrophy that reduces the size of the apical region of the LV cavity. Isolated apical HCM is not associated with LVOTO.

\section{Clinical management}

Dyspnoea, chest pain and syncope are typical symptoms found in HCM patients with LVOTO. Patients with obstruction should be advised to avoid dehydration and excessive alcohol consumption as volume depletion exacerbates the pressure gradient. Similarly, vasodilating drugs including nitrates should be avoided, as well as digoxin, which has positive inotropic effects. First-line medical therapy usually involves the administration of $\beta$-adrenergic blocking agents, which have both negative inotropic and negative chronotropic effects that help alleviate obstruction, and dosage should be titrated to the maximum tolerated (Elliott et al. 2014). Second line management is use of the calcium antagonist Verapamil, which improves ventricular relaxation and decreases LV contractility. Disopyramide is a type I-A antiarrhythmic agent with an anticholinergic effect, which is often used in combination with a $\beta$-blocker if this is only partially effective when used alone. In patients with a history of atrial fibrillation, it must be used in combination with an AV node blocker, as, with its use, episodes of atrial fibrillation may be accompanied by a rapid ventricular response.
Despite these treatments, patients may remain highly symptomatic due to incomplete effectiveness of the drugs or due to dose-limiting side effects. In this case, septal reduction therapy is generally recommended for HCM patients who continue to be in New York Heart Association functional classes III and IV despite maximum tolerated pharmacotherapy. Specifically, septal myectomy is indicated in HCM patients with a peak outflow gradient of $\leq 50 \mathrm{mmHg}$ as measured with Doppler echocardiography either under resting conditions or by physiological provocation through exercise (Maron et al. 2003). Moreover, the required minimum thickness of the interventricular septum required for surgery is specified at $15 \mathrm{~mm}$ (Marian and Roberts 2001). By restoring diastolic activity, septal myectomy is able to provide longterm alleviation of HCM-related symptoms. More recently, percutaneous alcohol septal ablation (ASA) has been introduced as alternative form of septal reduction therapy. This option is usually presented to patients at the same time as myectomy, and the patient must make an informed decision based on the advantages and disadvantages of the procedure, which will be discussed later.

Non-obstructive HCM is regarded as the predominant haemodynamic form of the disease on the basis of assessment of LVOT gradient under resting conditions or during physiological provocations such as Valsalva manoeuvre and exercise. In around $70 \%$ of clinical cases, neither the thickness nor location of the hypertrophied myocardium is sufficient to cause severe LVOTO, but approximately one-third of this HCM cohort will develop latent obstruction (Elliott et al. 2014). These HCM patients frequently present with LVOT gradient $<50 \mathrm{mmHg}$ in which pharmacotherapy is the preferred management for reducing symptoms, improving functional capacity and preventing disease progression. Approximately $25 \%$ of HCM patients have severe LVOTO, which is an indication for septal myectomy (Shah et al. 2008).

\section{Historical context}

Although HCM was described in earlier publications, the first detailed account of the condition was in 1958 by Teare when he reported the autopsy findings of the diseased myocardium in eight young patients who had died as a consequence of SCD (Teare 1958). He likened the disease to be a tumour of the heart with genetic predisposition. It is now recognised that LVOTO is an important mechanism responsible for the cardinal symptoms of dyspnoea, chest pain and syncope, and associated with SAM of the mitral valve leaflet resulting in mitral regurgitation (Melacini et al. 2010). Other important facets include diastolic dysfunction and arrhythmias. Early surgical intervention was focused on relieving this mechanical impedance to LV ejection via septal myotomy. This technique involved incising the prominent anterior muscular ridge of the 
interventricular septum and deepening the hypertrophied myocardium into the fissure where the edges are subsequently sutured together (Robbins and Stinson 1996). In 1968, Morrow and colleagues pioneered the surgical technique of limited transaortic septal myectomy (the "Morrow procedure") in which a limited region of hypertrophied myocardium at the basal septum was excised (Morrow et al. 1968). The contemporary transaortic myectomy procedure has developed the Morrow procedure further by extending the region of septal excision past the basal (subaortic) septum, and up to $3 \mathrm{~cm}$ from the aortic valve, allowing for better exposure of the distal extent of the hypertrophied septum (Dearani and Danielson 2005). Nonetheless, it may be difficult to relieve midventricular and apical HCM with this approach, and so additional techniques such as the transapical approach may be employed.

Historically, concomitant mitral valve replacement was proposed to resolve the associated SAM and mitral regurgitation (Cooley et al. 1976). However, it is now accepted that adequate septal myectomy is capable of correcting SAM and thus the mitral regurgitation in the majority of patients, and that mitral valve repair or replacement should only be undertaken for those patients with primary mitral valve pathology, such as mitral valve prolapse (Cavalcante et al. 2012).

\section{Surgical myectomy techniques}

\section{Intraoperative monitoring}

Intraoperative transesophageal echocardiography (TEE) is routinely used to assess the function of the mitral valve and degree of LVOTO before and after myectomy, and to reveal other abnormalities or complications such as iatrogenic ventricular septal defect (Ommen et al. 2002) (Fig. 1). Postresection LVOT gradient provocation with isoprenaline is a valuable intraoperative manoeuvre used to assess for an adequate myectomy that has abolished any latent obstruction, and, if any gradient is still present, it allows the surgeon to recommence cardiopulmonary bypass to extended myectomy. Transeptal needle puncture also allows for the measurement of any residual LVOT gradient following myectomy.

\section{Transaortic approach}

Extended LV septal myectomy via a transaortic approach is the standard surgical therapy for HCM patients. A median sternotomy is performed to gain access to the aorta and LV, and the patient is placed on cardiopulmonary bypass (CPB). The subaortic septum is then exposed through an oblique hockey-stick-shaped aortotomy that is made close to the sinotubular ridge (Dearani 2012) (Fig. 2). Stay sutures are used to retract the edges of the aortotomy, and a cardiotomy sucker is held across the aortic valve to retract the anterior leaflet of the mitral valve posteriorly. The first incision in the basal septum is made to the right of the nadir of the right aortic cusp in order to avoid the atrioventricular conduction system (Swistel and Balaram 2012) (Fig. 2). This is extended distally and then connected transversely leftwards to the anterior leaflet of the mitral valve, at which point scissors are used to complete the excision of this larger initial portion of myocardium. Next, the immediate subaortic area of septal excision is lengthened towards the apex of the heart, which is facilitated by depressing the right ventricle with a sponge-stick to bring the septum further into view. Alternatively, a hook may be employed to gently pull the septum into the surgeon's sight. By bringing the interventricular septum into clear view, another incision of the hypertrophied septum is made beyond the endocardial scar (which is the site of systolic contact of the mitral valve with the septum) to the midventricular level at the base of papillary muscles usually yielding a total of 3-12 g of muscle (Brown and Schaff 2008) (Fig. 2).

The LV is then flushed to remove any debris, and the aortic and mitral valves are inspected for any damage sustained during surgery. The aortotomy is then closed, and separation from CPB is completed. Simultaneous measurements of the aortic and LV pressures and assessment by TEE are carried out after discontinuation of CPB to confirm the adequacy of the resection, check for absence of a LVOT gradient, and resolution of any mitral regurgitation (Maron et al. 2011). Inadequate septal myectomy and omission of anomalous papillary muscles are frequent causes of residual and recurrent gradients. A satisfactory result is determined as laminar blood flow in the outflow tract, absence of SAM and a peak-to-peak gradient of $<10 \mathrm{mmHg}$ at rest (Merrill et al. 2000).

\section{Transapical approach}

In isolated midventricular HCM, the dynamic outflow tract obstruction is a consequence of systolic reduction in the midventricle from close apposition between the interventricular septum and the papillary muscles (Yuichi et al. 2007). Diagnosis is confirmed by detection of a LVOT gradient in the midcavity. Midventricular obstruction may also occur together with basal septal hypertrophy. As the midventricular region of the septum may be difficult to access through the transaortic approach, a transapical approach may be employed, either alone or in combination with a transaortic approach. In this approach, the left anterior descending coronary artery is identified, and a small apical ventriculotomy is made parallel and lateral to it (Said et al. 2012) (Fig. 3). Once the interventricular septum is exposed, myectomy is performed with careful attention to prevent injury to the mitral valve and its papillary muscle attachments (Fig. 3). In some patients, further resection is required along the free wall, and the anterolateral and posteromedial papillary muscles may be trimmed to improve diastolic filling (Kunkala et al. 2013). 


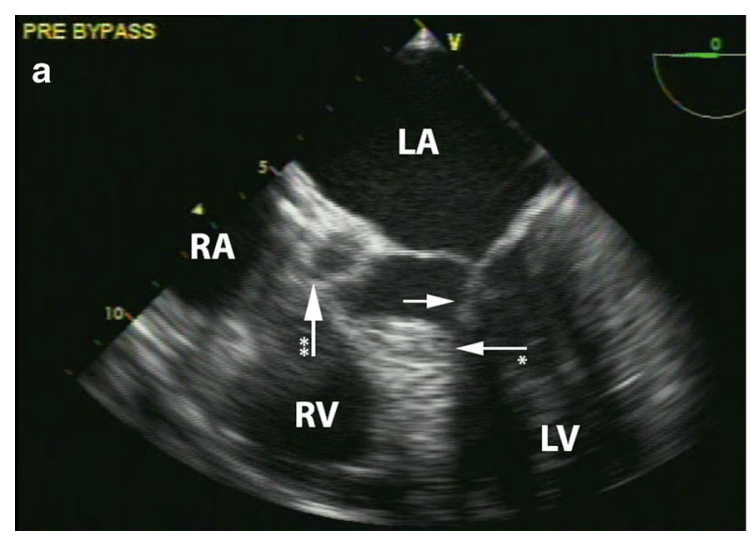

Fig. 1 Intraoperative transesophageal echocardiography (TEE) monitoring. a Pre-myectomy image demonstrating basal septal hypertrophy (* white arrow) and systolic anterior motion of the anterior mitral valve (white arrow) causing dynamic outflow tract obstruction.

Apical HCM is a morphological variant that can produce a narrow LV cavity, and patients usually have few symptoms. The indications for surgery in this subset includes demonstration of asymmetric left ventricular hypertrophy, confined predominantly to the LV apex with an apical wall thickness $\geq 15 \mathrm{~mm}$ and a ratio of maximal apical to posterior wall thickness $\geq 1.5$ (based on two-dimensional echocardiography or magnetic resonance imaging) (Eriksson et al. 2002). This occurs in around $3 \%$ of HCM patients (Yusuf et al. 2011). The surgical therapy is undertaken with a transapical approach in which the crucial goal is to achieve an augmented LV cavity size, thus correcting LV pressures and minimising wall stress. Hypertrophied muscle is resected from the interventricular

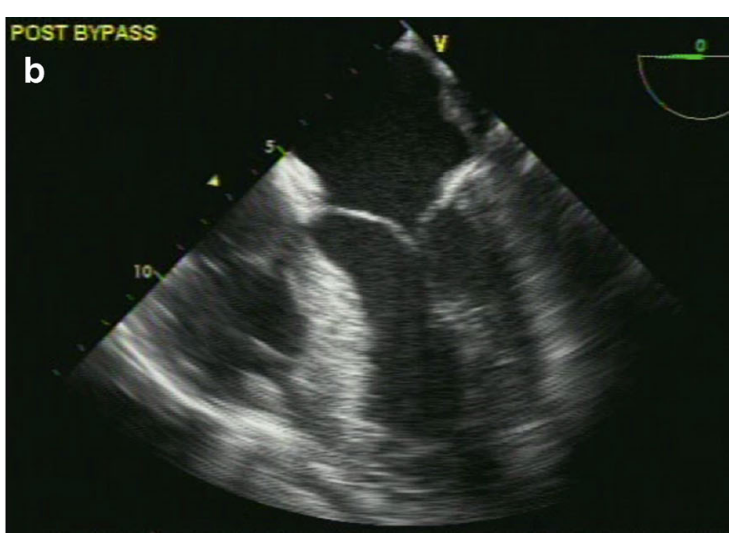

Right atrium $(R A)$, right ventricle $(R V)$, left atrium $(L A)$, left ventricle $(L V)$, aortic valve (** white arrow). b Post-myectomy image demonstrating basal septum resection and relief of outflow tract obstruction

septum and the free wall of the left ventricle to achieve enlargement of the left ventricular cavity (Fig. 4).

Transmitral approach

The transmitral approach has been attempted as an alternative to the standard transaortic approach used for subaortic obstruction. This technique is particularly applicable to paediatric cases of HCM, where the narrow aortic valve orifice limits the transaortic exposure and access to the obstruction (Altarabsheh et al. 2013; Theodoro et al. 1996). In this approach, the left atrium is opened through the atrioventricular groove on the patient's right side, extending the upper incision
Fig. 2 Transaortic myectomy for basal HCM. a View of the interventricular septum and outflow tract obstruction (labelled white arrow); right coronary leaflet $(R C)$, left coronary leaflet $(L C)$, and non-coronary leaflet $(N C)$ of the aortic valve. b Scalpel shown incising the basal septum, beginning to the right of the nadir of the right coronary leaflet and extending leftwards to avoid the atrioventricular conduction bundle. $\mathbf{c}$ Resected portion of the myocardium $(R M)$ being removed. d View of the septum post-myectomy showing relief of the obstruction; the nadir of the right coronary leaflet $(*$ white arrow); anterior mitral valve leaflet (** white arrow) retracted by cardiotomy sucker
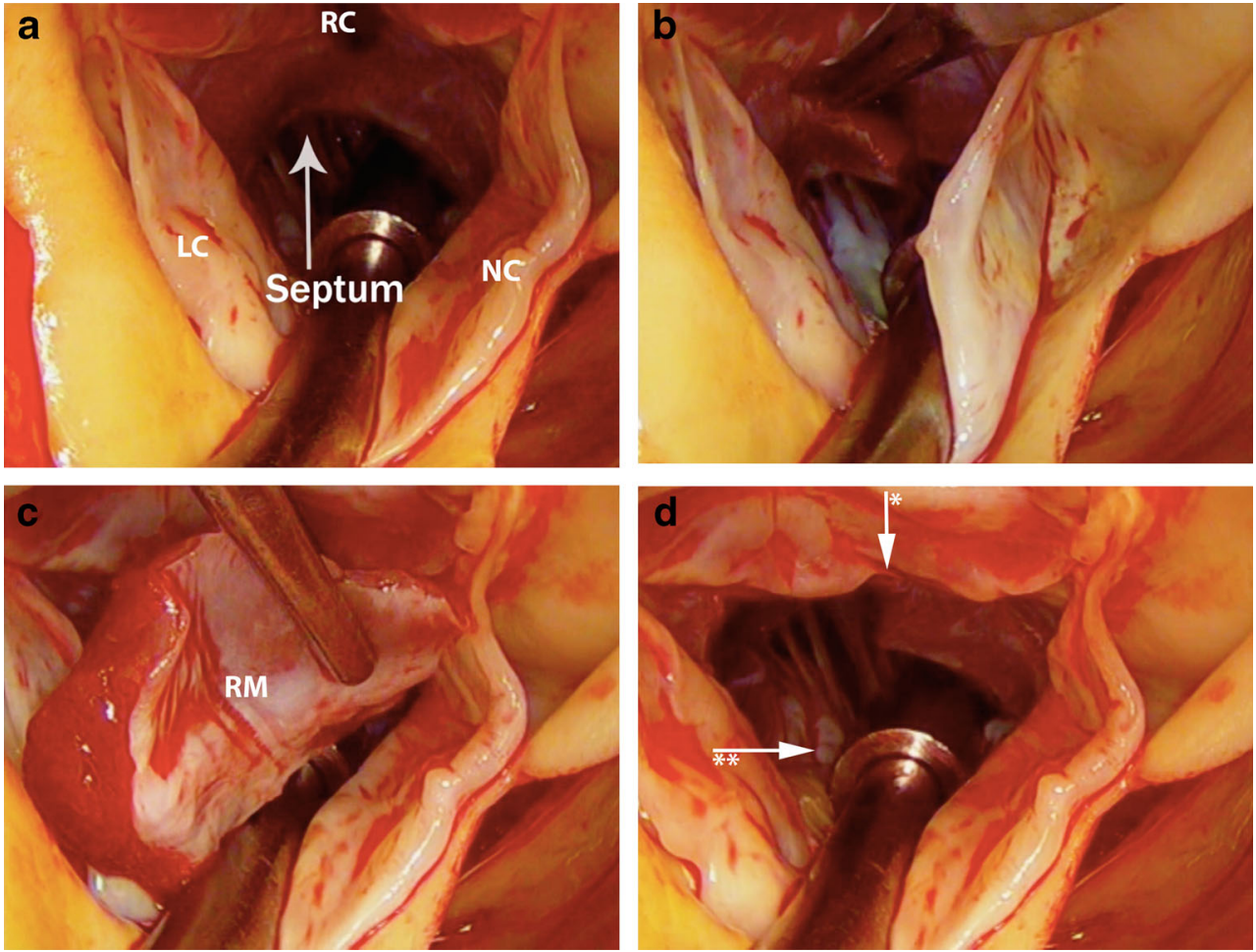

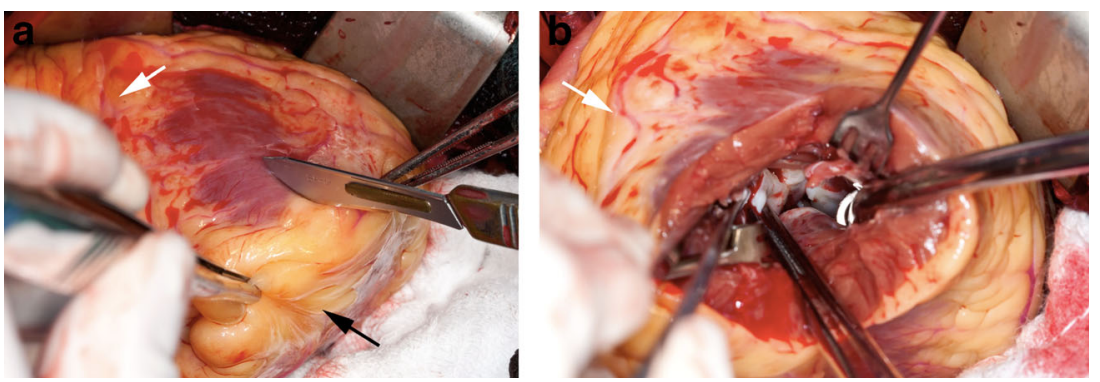

Fig. 3 Transapical myectomy for midventricular HCM. a Site of apical incision, made in a bare area parallel and lateral to the left anterior descending artery (white arrows), and cranial to the true left ventricular apex (black arrow). b Resection of midventricular portion of hypertrophied myocardium

medially behind the superior vena cava. Then, the anterior leaflet is detached from the annulus widely, but both commissures are left intact. Two traction sutures are placed to the detached edge of the anterior leaflet where it is retracted towards the surgeon on the patient's right. By looking for the endocardial thickening opposite to the mitral valve, the subaortic obstruction may be identified. A longitudinal incision is then made along the right side of hypertrophied myocardium and extended with scissors to resect the thickened septum bulging into the LV cavity.

\section{Adjuvant mitral valve surgery}

As previously indicated, mitral valve surgery may be required for HCM patients with associated abnormalities of the valvular apparatus, such as anomalous insertion of papillary muscles into the anterior leaflet and fusion of papillary muscles with the interventricular septum or free wall. In severe cases, extensive hypertrophy of papillary muscles leads to exaggerated anterior displacement of LV cavity (Ashikhmina et al. 2011). These variations contribute to tethering of the leaflets of the mitral valve, increasing the degree of LVOTO in HCM patients. As an adjunct to septal myectomy, mitral valve repair may entail resecting the posterior leaflet in the context of mitral valve prolapse or using artificial chordae to provide structural stability for anterior leaflet abnormalities. The main surgical principle is to separate connections between the subvalvular apparatus and the septum or free wall while maintaining the attachments to the anterior leaflet (Minakata et al. 2004). An annuloplasty ring may be required to minimise the risk of recurring SAM after the repair.

\section{Mobilisation of fibrous trigones}

Mobilisation of the fibrous trigones is an alternative surgical therapy to septal myectomy. Yacoub and colleagues first described this technique, noting the important roles of the left and right fibrous trigones in achieving durable relief of LVOTO (Yacoub et al. 1999). They postulated that LVOTO was derived from interference of the hinge mechanism that was provided by both fibrous trigones. In HCM patients, these two regions are linked together by progressive deposition of connective tissue. Therefore, the complete excision of this fibrous bridge is vital in facilitating sufficient mobilisation of the two fibrous trigones for the eradication of LVOTO. Initially, exposure is attained through an aortotomy at which point the aortic valve is inspected, and any fused commissures are segregated. The subaortic region is also probed for the presence of a fixed subaortic membrane. From below the base of the right coronary cusp, a vertical incision is made in the interventricular septum and continued deep into the ventricle to the level of anterior papillary muscles of the mitral valve (Hueb et al. 2002). The incision is then extended laterally to separate the left and right fibrous trigones. The effect is a thorough excision of the fibrous bridge and, as a result, the hinge mechanism between the septum and subaortic apparatus is released.

\section{Clinical outcomes}

Outcomes of an adequate septal myectomy include a major reduction of LVOTO, reduction in the associated mitral
Fig. 4 Transapical myectomy for apical HCM. a View through the apical incision prior to myectomy demonstrating thickened myocardium; left anterior descending artery (white arrow). b Post-myectomy demonstrating reduced myocardial thickness and increased cavity size
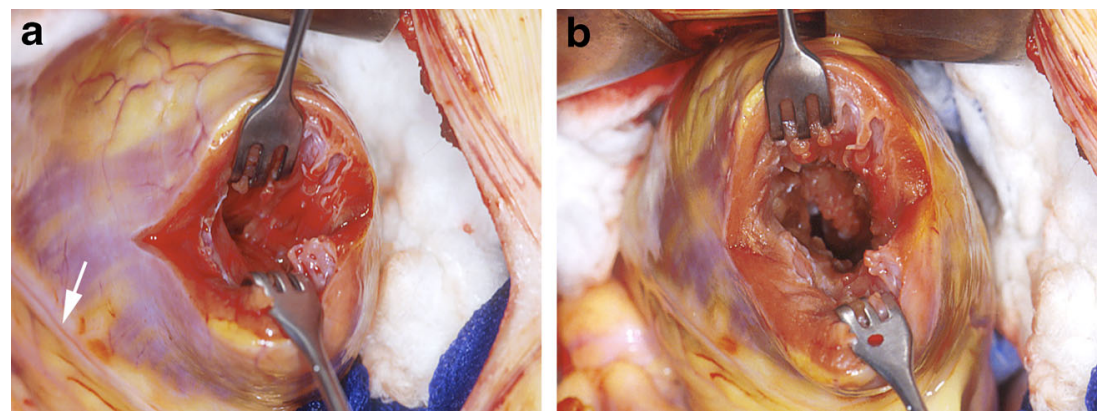
regurgitation and marked relief of symptoms (Woo et al. 2005). The evolution of the surgical techniques for HCM in the last $10-15$ years has produced a considerable reduction in operative mortality, to less than $2 \%$ in most studies (Table 1 ). The risk of operative mortality is greater in elderly HCM patients, and those requiring adjuvant surgical procedures, which may include aortic valve replacement, mitral valve repair and coronary artery bypass grafting. Following an HCM patient group with a mean age of $73.2 \pm 11.2$ years, the operative mortality of septal myectomy was found to be $2 \%$ (Kayalar et al. 2010). Contemporary studies have also shown that complications, such as heart block and iatrogenic ventricular septal perforation, are relatively uncommon with a reported morbidity rate of $<1-2 \%$ (Maron et al. 1978).

Table 1 presents mid- to long-term survival studies in large, contemporary case series of septal myectomy. As demonstrated, experienced centres are able to achieve 5-year survival rates greater than $90 \%$, and 10 -year survival rates greater than $80 \%$. In addition, reoperation rates were found to be $8.8,12.2$, 21.3 and $27.3 \%$ at 5, 10, 15 and 20 years, respectively (Altarabsheh et al. 2013). There is some evidence that myectomy may modify long-term survival, specifically through a reduction in the risk of arrhythmic sudden death, although this is controversial. Ommen and colleagues reported long-term survival in post-myectomy patients was comparable to that of an age-matched general population, and superior to patients with obstructive HCM managed conservatively (Ommen et al. 2005). While the incidence of both sudden (presumed arrhythmic) and heart failure-attributable deaths was lower in the surgical group, the analysis was retrospective, and there may be factors influencing management decisions of surgery or medical therapy that cannot be adjusted for, and may effect comparative long-term outcomes. Nevertheless, surgical myectomy was clearly shown to be associated with longevity equivalent to the general population, and may be considered at a minimum as producing very favourable long-term results.

The mechanism whereby amelioration of LVOTO may reduce SCD is unknown, but may relate to the reduction of arrhythmic substrate by debulking the LV mass, or to the normalization of intracavity pressures. McLeod and colleagues reported the incidence of ICD shocks in patients with or without myectomy (McLeod et al. 2007). During a median followup of 4.5 years, the survey revealed 12 patients $(17 \%)$ in the non-myectomy group and only 1 patient $(2 \%)$ in the myectomy group with appropriate ICD discharges. Hence, septal myectomy through its relief of LVOTO is also associated with reducing the incidence of appropriate ICD discharges.

Studies examining the long-term resolution of symptoms and heart failure after myectomy have also found it to produce effective and durable relief. Iacovini and colleagues found that, of 97 patients in New York Heart Association (NYHA) functional class III-IV before myectomy, 93 (96\%) were in class I-II at most recent evaluation $(P=0.001)$ (Iacovoni et al. 2012). Similarly, Desai and colleagues found that, following myectomy, 667 patients (96\%) remained asymptomatic or minimally symptomatic (NYHA class I or II) during long-term follow-up (Desai et al. 2013). Mohr and colleagues showed that myectomy patients have the capacity to attain near-normal exercise capacity and quality of life that is predictable and durable (Mohr et al. 1989). These benefits were demonstrated subjectively by patient history and objectively by increased treadmill time, maximum workload, and peak oxygen consumption, and also by improved myocardial oxygen demand, metabolism and coronary blood flow (Heric et al. 1995).

\section{Recurrent obstruction}

Recurrent LVOTO after septal myectomy is uncommon, although if it does occur it is usually the result of a limited initial

Table 1 Studies of mid- to long-term survival of septal myectomy

\begin{tabular}{llllll}
\hline Study & $n$ & Follow-up (years) & Early mortality (\%) & Survival at 5 years (\%) & Survival at 10 years (\%) \\
\hline Sedehi et al. 2014 & 171 & 13.7 & 2.9 & 92.9 & 81.1 \\
Desai et al. 2013 & 699 & $6.2 \pm 3$ & 0.0 & $94 \%$ at follow-up & 88.8 \\
Iacovoni et al. 2012 & 124 & Median: 1.7 (IQR 0.3-3.4) & 0.8 & 96.7 & 92 \\
Ross et al. 2012 & 132 & $4.2 \pm 3.2$ & 0.0 & 99 & 87.3 \\
Smedira et al. 2008 & 323 & $3.6 \pm 2.8$ & 1.4 & 92.5 & 82.9 \\
Woo et al. 2005 & 338 & $7.7 \pm 1.9$ & 1.5 & 95.1 & 83.3 \\
Ommen et al. 2005 & 289 & $6.2 \pm 6$ & 0.8 & 96.3 & 80.1 \\
Schoenbeck et al. 1998 & 110 & $11.7 \pm 7.5$ & 3.6 & 92.9 & 81.0 \\
Robbins and Stinson 1996 & 158 & $6.1 \pm 4.8$ & 3.2 & 90.1 & 87.7 \\
Schoendube et al. 1995 & 364 & 8.2 & 2.9 & 90.8 & 70.1 \\
Heric et al. 1995 & 178 & 3.7 & 6.2 & 96.2 & 88.2 \\
Schulte et al. 1993 & 364 & 8.2 & 4.9 & 93.0 & \\
\hline
\end{tabular}

${ }^{\text {a }}$ Values presented are mean \pm standard deviation, unless otherwise indicated 
myectomy that failed to extend the resection far enough towards the apex of the heart (Maron 2007). Notably, the potential for incomplete septal myectomy through the transaortic approach is higher in paediatric HCM patients because of the more limited exposure across the narrow aortic annulus. Other mechanisms of recurrent LVOTO include untreated septal hypertrophy at the midventricular level and the presence of anomalous papillary muscles. In a recent study, Minakata and colleagues reviewed a series of $13 \mathrm{HCM}$ patients who underwent repeat septal myectomy for recurrent LVOTO (Minakata et al. 2005) . The patients were followed up for an average of 5.8 years during which time there was only one late death. None of the surviving patients had recurrent LVOTO, and all were categorised in NYHA functional classes I and II (Bigelow et al. 1966). As such, repeat septal myectomy remains a safe and feasible treatment option for failed initial operations.

\section{Myectomy for latent obstruction}

Latent obstruction is described in HCM patients as the presence of a low resting LVOT gradient $(0-30 \mathrm{mmHg})$ that increases to over $50 \mathrm{mmHg}$ with the use of provocation such as exercise testing, Valsalva manoeuvre, and inhalation of amyl nitrite (Maron 2002). In a clinical study, Said and colleagues reviewed the role of septal myectomy in $249 \mathrm{HCM}$ patients with proven latent obstruction (Said et al. 2013). A group with latent obstruction was compared in follow-up after myectomy with another group who had a high resting gradient (>30 $\mathrm{mmHg}$ ) before undergoing septal myectomy. Interestingly, the study showed that the degree of functional improvement and late survival were similar for both groups of HCM patients (Seiler et al. 1991). Therefore, septal myectomy should be considered in HCM patients with disabling symptoms who have latent obstruction.

\section{Alcohol septal ablation (ASA)}

ASA is a percutaneous intervention that results in selective infarction of the interventricular septum by infusing approximate $1.5-3 \mathrm{~mL}$ of $100 \%$ alcohol into one of the left anterior descending artery septal perforators to relieve LVOTO. The technique requires a suitable anatomy in which a septal perforator supplies the site of maximum systolic flow velocity and also the site of SAM impingement on the septum. This occurs in approximately $70 \%$ of those evaluated for the procedure (Smedira et al. 2008). In this subgroup of patients, ASA has been demonstrated to be effective at reducing resting LVOT gradients (Leonardi et al. 2010). The major advantages of this less invasive treatment option are the avoidance of a sternotomy and the risks of $\mathrm{CPB}$, and reduced procedural pain. However, the intracoronary administration of ethanol causes a transmural region of dense scarring that is variably interspersed in the septal tissue. This effect may result in acute myocardial infarction with vascular necrosis, which becomes apparent on cardiac MRI with gadolinium enhancement (Valeti et al. 2007). In comparison, septal myectomy only produces a discrete area of resected tissue consistently localised to the anterior septum without creating potentially arrhythmogenic myocardial scarring (Maron 2007).

In a meta-analysis of comparative studies of ASA $(n=$ $183)$ and septal myectomy $(n=168)$, Alam and colleagues found that both groups had comparable improvement in NYHA functional class at follow-up $(1.5 \pm 0.3$ in ASA vs. $1.3 \pm 0.2$ in myectomy, $p=0.2$ ) (Alam et al. 2009). Both groups had similar baseline LVOT gradients $(81.4 \pm 14.3$ vs. $77.4 \pm 15.5 \mathrm{mmHg}$ ), and although the postoperative resting outflow gradient in both groups was $<0 \mathrm{mmHg}$ at follow-up, the septal myectomy group had a lower value $(18.2 \pm 6.7$ vs. $10.8 \pm 6.3 \mathrm{mmHg}, p<0.001)$. A higher percentage of patients undergoing ASA required permanent pacemaker implantation for complete heart block $(18.4 \pm 7.9$ vs. $3.3 \pm 3.9 \%, p=0.04)$. As such, this study concluded that ASA produces comparable clinical results to myectomy, but the very long-term effects of this procedure remain to be studied, especially with respect to late survival and ventricular arrhythmias (Alam et al. 2006).

Another meta-analysis performed a comparison of case series of ASA (19 studies, $n=2207)$ and myectomy ( 8 studies, $n=1887$ ) using a random effects model and regression analysis (Leonardi et al. 2010). They found similar all-cause mortality rate $(0.021$ events/patient-years in ASA vs. 0.018 in myectomy, $p=0.37$ ), and also SCD rate (0.004 events/patient-years in ASA vs. 0.003 in myectomy, $p=0.036$ ). However, patients who underwent ASA were older and had less septal hypertrophy, which, when adjusted for, resulted in an odds ratio for all-cause mortality (OR 0.28, $95 \%$ CI: 0.16 to 0.46 ) and SCD (OR 0.32, $95 \% \mathrm{CI}: 0.11$ to 0.97) favouring ASA. However, some individual studies have actually found an increased risk of SCD compared to myectomy, postulated to arise from the area of fibrosis created by the alcohol infusion (Antoun et al. 2009).

In summary, ASA is a less invasive technique that may be more suitable for elderly or high-risk patients than surgical myectomy because there may be reduced procedural all-cause mortality rate. However, there is an increased risk of heart block and permanent pacemaker requirement, and slightly higher post-procedural resting LVOT gradients, and thus myectomy remains the gold standard for durable relief of LVOTO and symptoms. 


\section{Conclusion}

HCM is a heterogeneous disease, with a variable pathology and clinical course. Nonetheless, advances in the understanding of the anatomical and pathophysiological basis of the disease have led to more effective therapeutic options. Septal myectomy is able to provide a substantial proportion of HCM patients with LVOTO relief of obstruction and symptoms, with low morbidity and excellent long-term survival. Although ASA is a less invasive procedure that is capable of relieving obstruction in a subset of patients, there is a high post-procedure requirement for permanent pacemaker implantation and the long-term survival rate is less well known. At this stage, surgical myectomy in experienced hands remains to be the gold standard therapy in the management of HCM.

\section{Compliance with ethical standards}

Conflicts of Interest James J. Wu, Michael Seco, Caroline Medi, Chris Semsarian, David R. Richmond, Joseph A. Dearani, Hartzell V. Schaff, Michael J. Byrom and Paul G. Bannon declare that they have no conflict of interest.

Ethical Approval This article does not contain any studies with human participants or animals performed by any of the authors.

\section{References}

Alam M, Dokainish H, Lakkis N (2006) Alcohol septal ablation for hypertrophic obstructive cardiomyopathy. A systematic review of published studies. J Interv Cardiol 19:319-327

Alam M, Dokainish H, Lakkis N (2009) Hypertrophic obstructive cardiomyopathy. Alcohol septal ablation vs. Myectomy. A meta-analysis. Eur Heart J 30:1080-1087

Altarabsheh S et al (2013) Outcome of septal myectomy for obstructive hypertrophic cardiomyopathy in children and young adults. Ann Thorac Surg 95:663-669

Antoun P, Masry HE, Breall J (2009) Sudden cardiac death complicating alcohol septal ablation. A case report and review of literature. Catheter Cardiovasc Interv 73:956-959

Ashikhmina E, Schaff H, Ommen S, Dearani J, Nishimura R, Abel M (2011) Intraoperative direct measurement of left ventricular outflow tract gradients to guide surgical myectomy for hypertrophic cardiomyopathy. J Thorac Cardiovasc Surg 142:53-59

Bigelow W, Trimble A, Auger P, Marquis Y, Wigle E (1966) The ventriculomyotomy operation for muscular subaortic stenosis. A reappraisal. J Thorac Cardiovasc Surg 52:514-524

Brown M, Schaff H (2008) Surgical management of obstructive hypertrophic cardiomypathy. The gold standard. Expert Rev Cardiovasc Ther 6:715-722

Cavalcante J, Barboza J, Lever H (2012) Diversity of mitral abnormalities in obstructive hypertrophic cardiomyopathy. Prog Cardiovasc Dis 54:517-522

Cooley D, Wukasch D, Leachman R (1976) Mitral valve replacement for idiopathic subaortic stenosis. Results in 27 patients. J Cardiovsac Surg 17:380-387

Dearani J (2012) Septal myectomy remains the gold standard. Eur Heart J 33:1999-2000
Dearani J, Danielson G (2005) Septal myectomy for hypertrophic cardiomyopathy. Oper Tech Thorac Cardiovasc Surg 9:278-292

Desai M, Bhonsale A, Smedira N, Naji P, Thamilarasan M, Lytle B, Lever $\mathrm{H}$ (2013) Predictors of long-term outcomes in symptomatic hypertrophic obstructive cardiomyopathy patients undergoing surgical relief of left ventricular outflow tract obstruction. Circulation 128: 209-216

Elliott P et al (2014) 2014 ESC guidelines on diagnosis and management of hypertrohpic cardiomyopathy. Eur Heart J 35:2733-2779

Eriksson M, Sonnenberg B, Woo A, Rakowski P, Parker T, Wigle E, Rakowski H (2002) Long-term outcome in patients with apical hypertrophic cardiomyopathy. J Am Coll Cardiol 39:638-645

Heric B, Lytle B, Miller D, Rosenkranz E, Lever H, Cosgrove D (1995) Surgical management of hypertrophic obstructive cardiomyopathy. Early and late results. J Thorac Cardiovasc Surg 110:195-206

Hueb A, Jatene F, Moreira L, Pomerantzeff P, Kallás E, Sd O (2002) Ventricular remodelling and mitral valve modifications in dilated cardiomyopathy. New insights from anatomic study. J Thorac Cardiovasc Surg 124:1216-1224

Iacovoni A et al (2012) A contemporary european experience with surgical septal myectomy in hypertrophic cardiomyopathy. Eur Heart J 33:2080-2087

Kayalar N, Schaff H, Daly R, Dearani J, Park S (2010) Concomitant septal myectomy at the time of aortic valve replacement for severe aortic stenosis. Ann Thorac Surg 89:459-464

Klues H, Schiffers A, Maron B (1995) Phenotypic spectrum and patterns of left ventricular hypertrophic in hypertrophic cardiomyopathy. Morphologic observations and significance as assessed by twodimensional echocardiography in 600 patients. J Am Coll Cardiol 26:1699-1708

Kunkala M, Schaff H, Nishimura R, Abel M, Sorajja P, Dearani J, Ommen S (2013) Transapical approach to myectomy for midventricular obstruction in hypertrophic cardiomyopathy. Ann Thorac Surg 96:564-570

Leonardi R, Kransdorf E, Simel D, Wang A (2010) Meta-analyses of septal reduction therapies for obstructive hypertrophic cardiomyopathy. Comparative rates of overall mortality and sudden cardiac death after treatment. Circulation 3:97-104. In this paper, Leonardi and colleagues performed systematic reviews for ASA and septal myectomy. The comparative data analyses were completed using a random effects model and regression analysis. Adjusted for baseline characteristics, the objective of the study was to compare overall survival and SCD rates after ASA or septal myectomy in a comprehensive and accurate manner

Marian A, Roberts R (2001) The molecular genetic basis for hypertrophic cardiomyopathy. J Mol Cell Cardiol 33:655-670

Maron B (2002) Hypertrophic cardiomyopathy. A systematic review. JAMA 287:1308-1320

Maron B (2007) Surgical myectomy remains the primary treatment option for severely symptomatic patients with obstructive hypertrophic cardiomyopathy. Circulation 116:196-206

Maron B, Maron M (2013) Hypertrophic cardiomyopathy. Lancet 381: $242-255$

Maron B, Merrill W, Freier P, Kent K, Epstein S, Marrow A (1978) Longterm clinical course and symptomatic status of patients after operation for hypertrophic subaortic stenosis. Circulation 57:1205-1213

Maron B, Gardin J, Flack J, Gidding S, Kurosaki T, Bild D (1995) Prevalence of hypertrophic cardiomyopathy in a general population of young adults. Echocardiographic analysis of 4111 subjects in the CARDIA study. Coronary artery risk development in (young) adults. Circulation 92:785-778

Maron B et al (2003) American college of cardiology/european society of cardiological clinical expert consensus document on hypertrophic cardiomyopathy. A report of the american college of cardiology foundation task force on clinical expert consensus documents and the european society of cardiology committee for practice 
guidelines. J Am Coll Cardiol 42:1687-1713. In this paper, Maron and colleagues have provided a perspective on the current state of management of patients with HCM. It is intended to inform medical professionals concerning the evolving areas of clinical practice and technologies that are widely available or new to the practice community. The detailed coverage of chosen topics are discussed with evidence-based approaches as evaluated by the American College of Cardiology (ACC) and European Society of Cardiology (ESC)

Maron B, Yacoub M, Dearani J (2011) Benefits of surgery in obstructive hypertrophic cardiomyopathy. Bring septal myectomy back for European patients. Eur Heart J 32:1055-1058

Maron B, Maron M, Semsarian C (2012) Genetics of hypertrophic cardiomyopathy after 20 years. Clinical perspectives. J Am Coll Cardiol 60:705-715

McLeod C et al (2007) Surgical septal myectomy decreases the risk for appropriate implantable cardioverter defibrillator discharge in obstructive hypertrophic cardiomyopathy. Eur Heart J 28:2583-2588

Melacini P et al (2010) Clinicopathological profiles of progressive heart failure in hypertrophic cardiomyopathy. Eur Heart J 31:2111-2123

Merrill W, Friesinger G, Graham T, Byrd B, Drinkwater D, Christian K, Benfer H (2000) Long-lasting improvement after septal myectomy for hypertrophic obstructive cardiomyopathy. Ann Thorac Surg 69: $1732-1735$

Minakata K, Dearani J, Nishimura R, Maron B, Danielson G (2004) Extended septal myectomy for hypertrophic obstructive cardiomyopathy with anomalous mitral papillary muscles or chordae. J Thorac Cardiovasc Surg 127:481-489

Minakata K, Dearani J, Schaff H, O'Leary P, Ommen S, Danielson G (2005) Mechanisms for recurrent left ventricular outflow tract obstruction after septal myectomy for obstructive hypertrophic cardiomyopathy. Ann Thorac Surg 80:851-856

Mohr R, Schaff H, Danielson G, Puga F, Pluth J, Tajik A (1989) The outcome of surgical treatment of hypertrophic obstructive cardiomyopathy. Experience over 15 years. J Thorac Cardiovasc Surg 97:666-674

Morrow A, Fogarty T, Braunwald E (1968) Operative treatment in idiopathic hypertrophic subaortic stenosis. Techniques and the results of preoperative and postoperative clinical and haemodynamic assessments. Circulation 37:589-596

Nishimura R, Holmes D (2004) Hypertrophic obstructive cardiomyopathy. N Engl J Med 351:1320-1326

Ommen S, Park S, Click R, Freeman W, Schaff H, Tajik A (2002) Impact of intraoperative transesophageal echocardiography in the surgical management of hypertrophic cardiomyopathy. Am J Cardiol 90: $1022-1024$

Ommen S et al (2005) Long-term effects of surgical septal myectomy on survival in patients with obstructive hypertrophic cardiomyopathy. J Am Coll Cardiol 46:470-476

Robbins R, Stinson E (1996) Long-term results of left ventricular myotomy and myectomy for obstructive hypertrophic cardiomyopathy. J Thorac Cardiovasc Surg 111:586-594

Ross RE, Sherrid MV, Casey MM, Swistel DG, Balaram SK(2012) Does surgical relief of obstruction improve prognosis for hypertrophic cardiomyopathy? Prog Cardiovasc Dis 54:529-534

Said S, Schaff H, Abel M, Dearani J (2012) Transapical approach for apical myectomy and relief of midventricular obstruction in hypertrophic cardiomyopathy. J Card Surg 27:443-448

Said S, Dearani J, Ommrn S, Schaff H (2013) Surgical treatment of hypertrophic cardiomyopathy. Expert Rev Cardiovasc Ther 11: $617-627$
Schoenbeck MH, Brunner-La Rocca HP, Vogt PR, Lachat ML, Jenni R, Hess OM, Turina MI (1998) Long-term follow-up in hypertrophic obstructive cardiomyopathy after septal myectomy. Ann Thorac Surg 65:1207-1214

Schoendube FA, Klues HG, Reith S, Flachskampf FA, Hanrath P, Messmer BJ (1995) Long-term clinical and echocardiographic follow-up after surgical correction of hypertrophic obstructive cardiomyopathy with extended myectomy and reconstruction of the subvalvular mitral apparatus. Circulation 92:122-127

Schulte HD, Bircks WH, Loesse B, Godehardt EAJ, Schwartzkopff B (1993) Prognosis of patients with hypertrophic obstructive cardiomyopathy after transaortic myectomy. J Thorac Cardiovasc Surg 106:709-717

Sedehi D, Finocchiaro G, Tibayan Y, Chi J, Pavlovic A, Kim YM, Tibayan FA, Reitz BA, Robbins RC, Woo J, Ha R, Lee DP, Ashley EA (2014) Long-term outcomes of septal reduction for obstructive hypertrophic cardiomyopathy.J Cardiol (in press)

Seiler C, Hess O, Schoenbeck M, Turina J, Jenni R, Turina M, Krayenbuehl H (1991) Long-term follow-up of medical versus surgical therapy for hypertrophic cardiomyopathy. A retrospective study. J Am Coll Cardiol 17:634-642

Shah J et al (2008) Prevalence of exercise-induced left ventricular outflow tract obstruction in symptomatic patients with non-obstructive hypertrophic cardiomyopathy. Heart 94:1288-1294

Smedira N et al (2008) Current effectiveness and risks of isolated septal myectomy for hypertrophic obstructive cardiomyopathy. Ann Thorac Surg 85:127-133

Spoladore R, Maron M, D'Amato R, Camici P, Olivotto I (2012) Pharmacological treatment options for hypertrophic cardiomyopathy. High time for evidence. Eur Heart J 33:1724-1733

Swistel D, Balaram S (2012) Surgical myectomy for hypertrophic cardiomyopathy in the 21 st century. The evolution of the RPR repair. Resection, plication and release. Prog Cardiovasc Dis 54:498-502

Teare D (1958) Asymmetrical hypertrophy of the heart in young adults. Br Heart J 20:1-8

Theodoro D, Danielson G, Feldt R, Anderson B (1996) Hypertrophic obstructive cardiomyopathy in paediatric patients. Results of surgical treatment. J Thorac Cardiovasc Surg 112:1589-1599

Valeti U et al (2007) Comparison of surgical septal myectomy and alcohol septal ablation with cardiac magnetic resonance imaging in patients with hypertrophic obstructive cardiomyopathy. J Am Coll Cardiol 49:350-357

Wigle E, Rakowski H, Kimball B, Williams W (1995) Hypertrophic cardiomyopathy. Clinical spectrum and treatment. Circulation 92: $1680-1692$

Woo A et al (2005) Clinical and echocardiographic determinants of longterm survival after surgical myectomy in obstructive hypertrophic cardiomyopathy. Circulation 111:2033-2041

Yacoub M, Onuzo O, Riedel B, Radley-Smith R (1999) Mobilisation of the left and right fibrous trigones for relief of severe left ventricular outflow obstruction. J Thorac Cardiovasc Surg 177:126-132

Yuichi S, Matsumoto N, Matsuo S, Yoda S, Kunimoto S, Satoshi S (2007) Midventricular hypertrophic obstructive cardiomyopathy presenting with acute myocardial infarction. Tex Heart Inst J 34: $475-478$

Yusuf S, Bathina J, Banchs J, Mouhayar E, Daher I (2011) Apical hypertrophic cardiomyopathy. World J Cardiol 3:256-259 